This is an Accepted Manuscript of an article published by Taylor \& Francis in Deviant Behavior on 29/01/2020, available online: https://doi.org/10.1080/01639625.2020.1722337

Citation for publication:

Reichelmann, Ashley V., James Hawdon, Matt Costello, John Ryan, Catherine Blaya, Vincente Llorent, Atte Oksanen, Pekka Räsänen, and Izabela Zych. 2020 (online). "Hate Knows no Boundaries: Content and Exposure to Online Hate in Six Nations.” Deviant Behavior. https://doi.org/10.1080/01639625.2020.1722337

\title{
Hate Knows No Boundaries: Online Hate in Six Nations
}

\author{
Ashley Reichelmann \\ Virginia Tech \\ James Hawdon \\ Virginia Tech \\ Matt Costello \\ Clemson University \\ John Ryan \\ Virginia Tech \\ Catherine Blaya \\ HEP du Canton de Vaud (Switzerland). \\ Vicente Llorent \\ University of Cordoba \\ Atte Oksanen \\ University of Tampere, Finland \\ Pekka Räsänen \\ University of Turku, Finland \\ Izabela Zych \\ University of Cordoba
}

The opinions, findings, conclusions, and recommendations expressed in this publication are those of the authors and do not necessarily reflect those of the Institute for Society, Culture and Environment.

*Address correspondence to James Hawdon (hawdonj@vt.edu), Center for Peace Studies \& Violence Prevention, 205A Norris Hall, Virginia Tech, Blacksburg, VA 24061. 


\title{
Hate Knows No Boundaries: Online Hate in Six Nations
}

\begin{abstract}
This paper examines cross-national commonalities and differences in online hate speech content, exposure, and emotional reaction. Using online surveys from 18 to 25 year old respondents in six countries, we find a majority of respondents were exposed to online hate in the preceding three months. Commonalities across countries are the platform where the respondents were exposed and how they arrived at such content. Unique national cultures of hate speech also exist, including the common targets and respondents’ emotional reactions. A majority of respondents report feeling angry, sad, or ashamed, but most worrisome may be the substantial numbers who report feelings of hatred or pride after seeing online hate. Given the potential for repeated exposure and the recent increase in hate crimes in the U.S. and Europe, this finding should serve as a reminder of the dangers of online hate and its potential link to offline violence.
\end{abstract}

Keywords: Hate speech; Extremism; Internet; Cross-national; Emotions 


\section{Hate Knows No Boundaries: Online Hate in Six Nations}

\section{Introduction}

The flow of information worldwide has reached unprecedented levels and, even as billions of users participate in this flow, governmental attempts at filtering information are increasing (Shahbaz 2018). These governmental attempts arise from the realization that the Internet has the potential to level cultural differences in ways that may be politically threatening, and, simultaneously, provide a forum to highlight group differences and forge particularistic identities (Schachtner 2014), often in opposition to other groups (Kaakinen et al. 2018; Zollo et al. 2017). It is in this context that we examine a particularly virulent form of Internet messaging: hate speech. Specifically, in this study, we examine hate speech across six nations characterized by high levels of Internet access and few governmental restrictions on content. Our aim is to search for cross-national commonalities and differences in the content of hate speech, levels of exposure, and emotional reactions to such exposure. The study goes beyond existing research on hate speech exposure, which is limited to findings from either one or just a very few countries.

\section{Background}

\section{The Ecology of Hate}

In 2017, hate crimes in the United States reached their highest level in more than a decade (Federal Bureau of Investigation 2018; Levin and Grisham 2017; Potok 2018), while also increasing in Europe over the same period (Engel et al. 2018). Numerous scholars and social commentators have linked hate crimes to hateful speech and extremist ideas (Foxman and Wolf 2013; Freilich, Belli, and Chermak 2011; International Security Program 2015; Singh and Singh 2012). And, as extremists use social media to champion their cause, recruit members, advocate 
violence, and create international extremist communities (Burris, Smith, and Strahm 2000;

Hussain and Saltman 2014), the number of people being exposed to such materials online appears to be increasing (Costello, Rukus, and Hawdon 2018; Potok 2018). Yet, there is little research that documents how many people are exposed to hateful messages, the frequency with which they are exposed, where they are exposed, how they arrive at the sites containing the material, who are the targets of the hate, and how those exposed emotionally react to the hate materials they see. Current research findings on these questions are mainly restricted to Englishspeaking countries. Moreover, there are even fewer attempts to track these phenomena crossnationally (for exceptions, see Hawdon, Oksanen, and Räsänen 2017; Keipi et al. 2017; Oksanen et al. 2018). To help address this gap, we report the results of online surveys covering a wide range of issues related to online hate, which were fielded in Finland, France, Poland, Spain, the United Kingdom, and the United States.

\section{Online Extremism: Its Nature, Types, and Dangers}

Unlike cyberbullying or cyberstalking that targets individuals, online hate focuses on a collective (Räsänen et al. 2016). It most commonly demeans or degrades a group and its members based on their race/ethnicity, national origin, sexual orientation, gender, gender identity, religion, or disability status. Both individuals and organized hate groups spread online hate through a variety of means, including, but not limited to, websites, blogs, social networking sites (SNS), listservs, news groups, and online video games (Costello et al. 2018; Franklin 2010).

Online hate exposure is often disturbing for those who witness it. Previous studies have found that the intensity of such negative experiences is stronger for women and immigrants (Savimäki et al. 2018). Those exposed to online hate also report lower trust in other people (Näsi et al. 2015) and the government (Costello et al. 2018) as well as higher levels of societal fear 
(Oksanen et al. 2018). In addition, exposure to hate materials correlates with several problematic behaviors and attitudes (Foxman and Wolf 2013, Näsi et al. 2015), including the rise of communal narratives of hate that justify hatred and violence toward targeted groups (Maitra and McGowan 2012).

A growing body of literature (e.g. Costello, Hawdon, and Cross 2017; Costello et al. 2018; Hawdon, Bernatzky, and Costello 2019; Hawdon, Oksanen, and Räsänen 2014; Hawdon et al. 2017; Keipi et al. 2017; Oksanen et al. 2014; Räsänen et al. 2016) indicates that exposure increases as users enter virtual spaces containing materials that advocate violence, self-harm, or other anti-social attitudes or behaviors. Similarly, frequent SNS use and spending long hours on the Internet as well as using specific Internet services, such as Facebook or YouTube, also increase the likelihood of exposure (Costello, Hawdon, and Ratliff 2017). Other individual-level correlates of exposure, at least in the U.S., include having higher levels of education, being Hispanic, and living alone (Hawdon et al. 2014; Hawdon et al. 2017). In addition, offline association with racist and delinquent peers is strongly related to self-reported exposure (Schils and Pauwels 2014).

Given the mounting evidence that exposure to online extremism can be an early step in the processes of radicalization, it is important to assess the extent to which people are exposed to these messages. While a growing body of literature has documented who is exposed in the U.S. and in a limited number of European nations, we lack comparable observations on not just levels of exposure to hate, but also the nature of that exposure and reactions to it cross-nationally (Keipi et al. 2017, Hawdon et al. 2017, and Oksanen et al. 2018 are exceptions). This study helps to address this gap in the literature. 


\section{Methods}

Data were collected between May 8 and May 18, 2018 from a Survey Sampling International (SSI) panel. SSI recruits potential participants through random digit dialing, banner ads, and other permission-based techniques. Randomly selected panel members between the ages of 18 and 25 in our six countries of interest participated in the survey.

Online proportional sampling panels_-pre-recruited non-probability samples intended to be demographically balanced on important population characteristics - are found to be as reliable as random probability-based sampling. Previous work found evidence that probability and nonprobability sampling yields similar results when using particular internet surveying platforms (Simmons and Bobo 2015; Weinberg, Freese, and McElhattan 2014). These platforms ensure one-time participation through IP address matching (Evans and Mathur 2005; Wansink 2001), and also weed out speeders through attention checks and mean timing comparisons to the sample. Also, the methods for recruitment, including pre-panel interviews and participation incentives, ensure serious interest in participation, and this has been found to increase the response validity of the overall data (see Wansink 2001; for a different view on non-probability samples, see MacInnis et al. 2018).

The samples from all nations were disproportionately comprised of females, ranging from 59 to 72 percent female. To correct for this, sample weights were constructed based on the percentage female in each nation between the ages of 18 and 25, which closely matches our samples' age range of 18-25. Data for the weight constructions were taken from the CIA's World Factbook (2018), which provided gender distributions for various age ranges. The average age for the sample is 21.65 years, with a standard deviation of 2.26 years. The analyzed sample is comprised of 2,592 individuals in Finland (247), France (487), Poland (389), Spain 
(387), the United Kingdom (515), and the United States (567). These countries were selected due to their high levels of Internet access and limited governmental restrictions on content. All questions analyzed below and their response categories are presented in the Appendix.

\section{Results}

\section{How many are exposed to online hate?}

Respondents were asked, “In the past 3 months, have you seen hateful or degrading writings or speech online that attacked certain groups of people or individuals?” Figure 1 shows considerable variation across the nations. France and the United Kingdom had significantly lower rates than the other nations, and Finland had significantly higher rates than other nations.

[Figure 1 near here]

\section{How frequently do people see hate?}

Next, respondents were asked, "How frequently do you see material online that expresses negative views toward some group?” Respondents in the United States and Finland reported seeing hate materials the most, as $23.9 \%$ and $20.3 \%$, respectively, report seeing it "frequently." Only in Poland did fewer than $10 \%$ of respondents say they saw such materials frequently. It is also noteworthy that $17 \%$ of Spanish respondents and nearly $16 \%$ of respondents from the United Kingdom reported that they "never" see such materials. These results are presented in Figure 2.

[Figure 2 near here] 


\section{What type of hate is seen?}

Respondents were then asked to report the type of hate they had seen. Specifically, they were asked, "Thinking of the most recent time when you saw or heard negative views expressed about a group, how would you best describe those views?” Being exposed to materials that use stereotypes to describe groups was the most common type of hate observed (43.7\%), while materials that openly advocated violence (23.5\%) and directly called for discrimination against a group (19.2\%) were viewed by the fewest respondents (See Table 1). There was, however, variation by country. The highest levels of exposure to all types of hate content were concentrated in Finland, Spain, and the United States, while the United Kingdom had the lowest percentage in three of the six types of hate expression. For example, in Finland, respondents reported the highest levels of exposure to material that advocated hatred of a group (43.4\%) and that used stereotypes to describe groups (56.3\%). These percentages were the highest by far in comparison to other nations. In Spain, respondents reported the highest levels of being exposed to material that advocated violence against a group (35.4\%) and materials that called for discrimination against a group (28.7\%). In the United States, respondents reported the highest levels of exposure to materials that blamed the group for both personal problems (36.0\%) and national problems (31.9\%). Overall, the cross-national comparison demonstrates that there are a range of different types of hate expressed in online material, and exposure seems to be moderated, in part, by nation.

[Table 1 near here] 


\section{What is the focus of the hate?}

Respondents were also asked what groups were targeted in the hate materials they most recently saw. Table 2 summarizes the responses to the question, "Did the negative views that you saw or heard online pertain to one or more of the following?” The results reveal that hate takes on a national flavor. In Finland, for example, slightly over half (50.6\%) of the hate materials seen most recently by respondents attacked nationality or immigrant status, while sexual orientation was a distant second focus of the hate Finnish respondents saw. In the United States and the United Kingdom, hate is mostly directed towards race and ethnicity (49.6\% and 39.0\%, respectively), while in Spain hate focusing on sexual orientation (42.1\%) and sex or gender identity (42.6\%) are most frequently seen. In both France and Poland, the focus of hate is more evenly distributed among targeted groups. In both nations, hate targeting race/ethnicity, nationality/immigrant status, and sexual orientation are all common and reported by similar percentages of respondents. While cross-national variation is evident, the characteristics most frequently targeted across all six nations are race/ethnicity (37.2\% of total sample), sexual orientation (34.3\%), and nationality/immigrant status (32.9\%).

[Table 2 near here]

\section{Where do people see hate?}

Figure 3 represents the online services or platforms where respondents most recently saw or heard negative views expressed. Facebook was identified by far as the most common location where hate materials were viewed. For instance, approximately 55\% of respondents in Poland, just over 40\% in Finland, France, and the United States, and just under 40\% in Spain and the United Kingdom reported Facebook as the most recent online location where they viewed hateful content. This makes sense because Facebook is the most popular platform on the internet. The 
next highest location of exposure oscillates between YouTube (in Finland, Poland, and the United States), Instagram (in Spain), and Twitter (in France and the United Kingdom). The platform where respondents report the least amount of exposure is Snapchat.

[Figure 3 near here]

\section{How do people get to the hate?}

Respondents were asked, "Which of the following best describes how you initially got to where you saw or heard this material?" and they could choose from the responses "I searched for it” or "I accidentally came across it." From Figure 4, it is clear that the vast majority of respondents arrived at the hate-containing site accidently. In every nation except Finland, 84 percent or more of the respondents reported doing so. In contrast, over a quarter (27.8\%) of Finnish respondents actively searched for the hate materials. This finding demonstrates how easy it is to come across such material while using the Internet. In addition, this finding reveals that many of those exposed to hate materials can be considered "victims" in that they are not actively seeking out the materials, but rather being passively exposed to them.

[Figure 4 near here]

\section{How does exposure make respondents feel?}

Exposure to hate material correlates with several emotions. Respondents were provided with the prompt "how did seeing this material make you feel?" and then given a list of emotions (see Table 3 or Appendix for complete list). For each, they were told to "indicate how you felt by sliding the slider to the appropriate spot on the scale,” which ranged from 0 to 100 . As seen in Table 3, the most common emotions felt overall from viewing the hate material were: anger 
(65\%), sadness (64.8\%), and shame (51.0\%). Pride (17.0\%) and guilt (22.6\%) were the least commonly felt. In individual countries, the most prominent emotion among respondents within country was split between sadness in Finland (56.7\%), Poland (55.1\%), and the United States (66.8\%), and anger in France (67.6\%), Spain (73.4\%), and United Kingdom (67.6\%). The emotions of anger, hatefulness, sadness, and shame were experienced by over $40 \%$ of respondents in nearly all countries. The exceptions were that hatefulness was only experienced by $28.8 \%$ of respondents in Poland and 39.8 percent in the United Kingdom.

[Table 3 near here]

\section{Discussion}

This study offers key insights into the realm of online hate cross-nationally. Our study provides comparable findings from six countries, some of which have not been studied before from this perspective. Our surveys reveal that while some attributes of online hate transcend borders, such as the SNS where hate is commonly seen or how people arrive at it, others are unique to each country. For example, there are differences as to what groups are commonly targeted, or how people respond emotionally to seeing hate. Perhaps most notably, we find that a majority - and in most cases nearly two-thirds - of respondents in the six nations we explored were exposed to online hate in the preceding three months. In addition, most respondents in all nations were exposed to hate at least occasionally, and most arrived at the sites containing this hate accidently.

Our results are alarming, given the potential that repeated exposure to hateful material may be personally distressing. Large proportions of our respondents reported feeling angry, hateful, sad, or ashamed after seeing online hate, while other sizeable amounts felt scared or fearful. Most worrisome, however, is that non-negligible shares of respondents reported feeling 
proud after seeing hate online. In fact, over one-fifth of respondents in the U.S. reported pride upon encountering hate. Given the increase in hate crimes and what is believed to be the mainstreaming of white-nationalism in the U.S. over the past few years (see, for example, Reitman 2018), this finding should serve as a reminder of the potential dangers of online hate and its plausible link to offline violence.

This work adds to our understanding of online hate in an international and multicultural context. While these topics have previously been explored in the United States or a few European nations, they have yet to be broached in an international, comparative context. Yet our study shows that Internet-based hate speech does not respect international boundaries, and, as a result, there are many similarities across the six nations. At the same time, there are indications of unique national cultures of hate speech, the causes and consequences of which deserve further exploration.

Declaration of Conflicting Interest: The authors declare that there is no conflict of interest.

Funding: This work was supported by the Institute for Society Culture and Environment at Virginia Tech under The ISCE Scholars Grant Program. 


\section{REFERENCES}

Burris, Val, Emery Smith, and Ann Strahm. 2000. "White Supremacist Networks on the Internet.” Sociological Focus 33 (2):215-235. doi: 10.1080/00380237.2000.10571166

Central Intelligence Agency. 2018. The World FactBook. Washington D.C.: Central Intelligence Agency. (https://www.cia.gov/library/publications/download/download-2018/index.html).

Costello, Matthew, James Hawdon, and Thomas N. Ratliff. 2017. “Confronting Online Extremism: The Effect of Self-Help, Collective Efficacy, and Guardianship on Being a Target for Hate Speech.” Social Science Computer Review 35 (5):587-605. doi: $10.1177 / 0894439316666272$

Costello, Matthew, James Hawdon, and Amanda Cross. 2017. "Virtually Standing up or Standing By? Correlates of Enacting Social Control Online.” International Journal of Criminology and Sociology 6:6-28.

Costello, Matthew, Joseph Rukus, and James Hawdon. 2018. “We Don’t Like Your Type around Here: Regional and Residential Differences in Exposure to Online Hate Material Targeting Sexuality.” Deviant Behavior 40 (3):385-401. doi: 10.1080/01639625.2018.1426266

Engel, Vlaray, Jean-Yves Camus, Matthew Feldman, William Allchorn, Anna Castriota, Ildikó Barna, Bulcsú Hunyadi, Patrik Szicherle, Farah Rasmi, Vanja Ljujic, et al. 2018. Xenophobia, Radicalism, and Hate Crime in Europe, Annual Report. Moscow: Editus.

Evans, Joel R., and Anil Mathur. 2005. "The Value of Online Surveys." Internet Research 15 (2):195-219. doi: 10.1108/10662240510590360 
Federal Bureau of Investigation. 2018. “Annual Hate Crime Reports 1996-Present.” Uniform Crime Reports. Retrieved August 7, 2018. (https://ucr.fbi.gov/hate-crime).

Foxman, Abraham, and Christopher Wolf. 2013. Viral Hate: Containing its Spread on the Internet. New York: Macmillan.

Franklin, Raymond. 2010. “The Hate Directory.” Woodstock, MD: Self-published. Retrieved October 14, 2014. (http://www.hatedirectory.com/).

Freilich, Joshua, Roberta Belli, and Steven Chermak. 2011. United States Extremist Crime Database. (ECDB) 1990-2010. College Park, MD: START: National Consortium for the Study of Terrorism and Responses to Terrorism. Retrieved August 7, 2018. (https://www.start.umd.edu/research-projects/united-states-extremist-crime-database-ecdb1990-2010).

Hawdon, James, Colin Bernatzky, and Mathew Costello. 2019. “Cyber-routines, Political Attitudes, and Exposure to Violence-Advocating Online Extremism.” Social Forces 98 (1):329-354. doi: 10.1093/sf/soy115

Hawdon, James, Atte Oksanen, and Pekka Räsänen. 2014. “Victims of Online Hate Groups: American Youth’s Exposure to Online Hate Speech.” Pp. 165-182 in The Causes and Consequences of Group Violence: From Bullies to Terrorists, edited by James Hawdon, John Ryan, and Mark Lucht. Lanham, MD: Lexington Books.

-----. 2017. "Exposure to Online Hate in Four Nations: A Cross-National Consideration.” Deviant Behavior 38 (3):254-266. doi: 10.1080/01639625.2016.1196985 
Hussain, Ghaffar, and Erin Marie Saltman. 2014. Jihad Trending: A Comprehensive Analysis of Online Extremism and How to Counter it. London: Quilliam International.

International Security Program. 2015. Homegrown Extremists. Washington D.C.: New America. Retrieved September 17, 2017. (http://securitydata.newamerica.net/extremists/deadlyattacks.html).

Kaakinen, Markus, Anu Sirola, Lina Savolainen, and Atte Oksanen. 2018. ”Shared Identity and Shared Information in Social Media: Development and Validation of the Identity Bubble Reinforcement Scale.” Media Psychology 1:25-51. doi: 10.1080/15213269.2018.1544910.

Keipi, Tao, Matte Näsi, Atte Oksanen, and Pekka Räsänen. 2017. Online Hate and Harmful Content: Cross-National Perspectives, $1^{\text {st }}$ edition. New York: Routledge.

Levin, Brian, and Kevin Grisham. 2017. Final US Status Report: Hate crime analysis \& forecast 2016/2017. San Bernandino, CA: Center for the Study of Hate and Extremism. Retrieved August 7, 2018 (https://csbs.csusb.edu/sites/csusb_csbs/files/Final\%20Hate\%20Crime\% 2017\%20Status\%20Report\%20pdf.pdf).

Maitra, Ishani, and Mary Kate McGowan, eds. 2012. Speech and Harm: Controversies over Free Speech. Oxford: Oxford University Press.

MacInnis, Bo, Jon Krosnick, Annabell S. Ho, and Mu-Jung Cho. 2018. “The Accuracy of Measurements with Probability and Nonprobability Survey Samples: Replication and Extension.” Public Opinion Quarterly 82 (4):707-744. doi: 10.1093/poq/nfy038 
Näsi, Matti, Pekka Räsänen, James Hawdon, Emma Holkeri, and Atte Oksanen. 2015. “Exposure to Online Hate Material and Social Trust Among Finnish Youth.” Information Technology \& People 28 (3):607-628. doi: 10.1108/ITP-09-2014-0198

Oksanen, Atte, James Hawdon, Emma Holkeri, Matti Näsi, and Pekka Räsänen. 2014. “Exposure to Online Hate Among Young Social Media Users.” Sociological Studies of Children \& Youth 18:253-273. doi: 10.1108/S1537-466120140000018021

Oksanen, Atte, Markus Kaakinen, Jaana Minkkinen, Pekka Räsänen, Bernard Enjolras, and Karl Steen-Johnsen. 2018. "Perceived Societal Fear and Cyberhate after the November 2015 Paris Terrorist Attacks.” Terrorism \& Political Violence. doi: 10.1080/09546553.2018. 1442329.

Potok, Mark. 2017. The Year in Hate and Extremism. Montgomery, AL: Intelligence Report, Southern Poverty Law Center. Retrieved November 19, 2017 (https://www.splcenter.org/fighting-hate/intelligence-report/2018/year-hate-and-extremism).

Räsänen, Pekka, James Hawdon, Emma Holkeri, Matti Näsi, Tao Keipi, and Atte Oksanen. 2016. ”Targets of Online Hate: Examining Determinants of Victimization Among Young Finnish Facebook Users.” Violence \& Victims 31 (4):708-726. doi:10.1891/0886-6708.VVD-14-00079.

Reitman, Janet. 2018. “U.S. Law Enforcement Failed to See the Threat of White Nationalism. Now They Don’t Know How to Stop it.” New York Times Magazine, November 3. Retrieved November 4, 2018. (https://www.nytimes.com/2018/11/03/magazine/FBI-charlottesvillewhite-nationalism-far-right.html). 
Savimäki, Tuukka, Markus Kaakinen, Pekka Räsänen, and Atte Oksanen. 2018. ”Disquieted by Online Hate: Negative Experiences of Finnish Adolescents and Young Adults.” European Journal on Criminal Policy and Research. doi: 10.1007/s10610-018-9393-2.

Schachtner, Christina. 2014. “Transculturality in the internet: Culture flows and virtual publics.” Current Sociology 63 (2):228-243. doi: 10.1177/0011392114556585

Schils, Nele, and Lieven Pauwels. 2014. "Explaining Violent Extremism for Subgroups by Gender and Immigrant Background, Using SAT as a Framework." Journal of Strategic Security 7 (3):27-47. doi: 10.5038/1944-0472.7.3.2

Shahbaz, Adrian. 2018. “The Rise of Digital Authoritarianism.” Freedom on the Net 2018. Washington D.C.: Freedom House. Retrieved November 26, 2018 (https://freedom house.org/sites/default/files/FOTN_2018_Final\%20Booklet_11_1_2018.pdf).

Simmons, Alicia, and Lawrence Bobo. 2015. “Can Non-full-probability Internet Surveys Yield Useful Data? A Comparison with Full-probability Face-to-face Surveys in the Domain of Race and Social Inequality Attitudes.” Sociological Methodology 45 (1):357-387. doi: $10.1177 / 0081175015570096$

Singh, Handsdeep, and Simran Jeet Singh. 2012. “The Rise of Hate Crimes Can Be Tied Directly to Hateful Speech.” The Daily Beast, September 6. Updated on July 13, 2017. Retrieved August 7, 2018 (https://www.thedailybeast.com/the-rise-of-hate-crimes-can-be-tied-directlyto-hateful-speech).

Wansink, Brian. 2001. “Editorial: The Power of Panels.” Journal of Database Marketing \& Customer Strategy Management 8 (3):190-194. doi: 10.1057/palgrave.jdm.3240034 
Weinberg, Jill, Jeremy Freese, and David McElhattan. 2014. “Comparing Data Characteristics and Results of an Online Factorial Survey between a Population-Based and a CrowdsourceRecruited Sample.” Sociological Science 1:292-310.

Zollo, Fabiano, Alessandro Bessi, Michela Del Vicario, Antonio Scala, Guido Caldarelli, Louis Shekhtman, and Walter Quattrociocchi. 2017. "Debunking in a World of Tribes.” PLOS|ONE 12 (7):e0181821. doi: 10.1371/journal.pone.0181821 


\section{APPENDIX: SURVEY ITEMS AND CODING}

\section{Exposure}

In the past 3 months, have you seen hateful or degrading writings or speech online that attacked certain groups of people or individuals?

$$
\begin{aligned}
& 1=\text { Yes } \\
& 2=\text { No }
\end{aligned}
$$

\section{Frequency of Exposure}

How frequently do you see material online that expresses negative views toward some group?

$$
\begin{aligned}
& 1=\text { I never see this type of material } \\
& 2=\text { I see this type of material very infrequently } \\
& 3=\text { I see this type of material occasionally } \\
& 4=\text { I see this type of material frequently }
\end{aligned}
$$

\section{Type of Hate Seen}

Thinking of the most recent time when you saw or heard negative views expressed about a group, how would you best describe those views? (check all that apply)

$$
\begin{aligned}
& 1=\text { They advocated violence against the group } \\
& 2=\text { They used stereotypes to describe the group } \\
& 3=\text { They blamed the group for their problems } \\
& 4=\text { They blamed the group for the nation's problems } \\
& 5=\text { They advocated hatred of the group } \\
& 6=\text { They called for others to discriminate against the group }
\end{aligned}
$$

\section{Focus of Hate}

Did the negative views that you saw or heard online pertain to one or more of the following? (Check all that apply)

$$
\begin{aligned}
& 1=\text { Ethnicity or race } \\
& 2=\text { Nationality or immigrant status } \\
& 3=\text { Sexual orientation } \\
& 4=\text { Religious conviction/ belief } \\
& 5=\text { Political views } \\
& 6=\text { Sex/Gender/Gender Identity } \\
& 7=\text { Disability } \\
& 8=\text { Appearance } \\
& 9=\text { Other }
\end{aligned}
$$




\section{Where people see hate}

Still thinking of the last time you saw or heard negative views online, on which of the following services did you see or hear these views? (check all that apply)

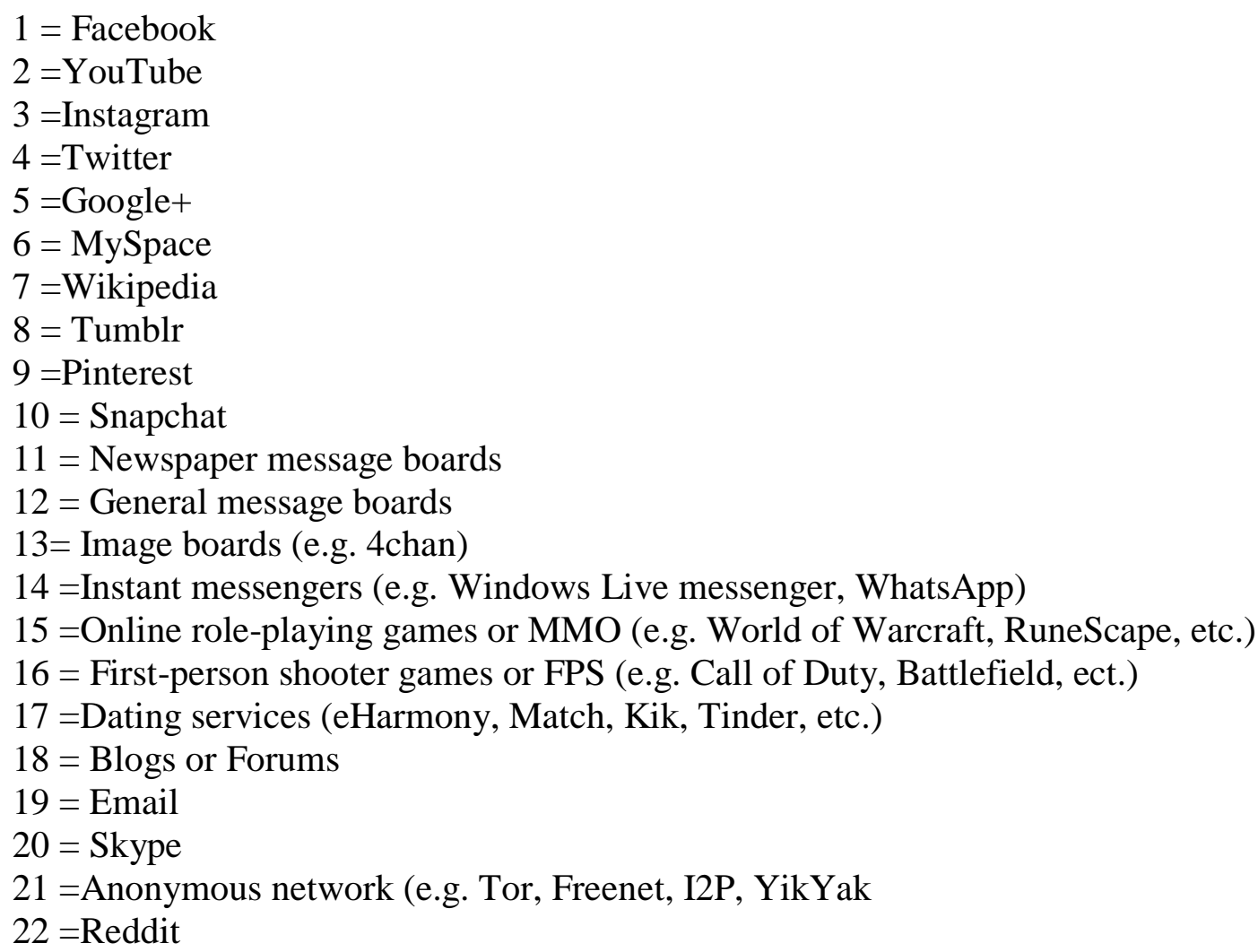

\section{How arrive at site where hate was seen}

Which of the following best describes how you initially got to where you saw or heard this material?

$$
\begin{aligned}
& 1=\text { I searched for it } \\
& 2=I \text { accidentally came across it }
\end{aligned}
$$

\section{How exposure made respondents feel}

How did seeing this material make you feel? For each of the following, please indicate how you felt by sliding the slider to the appropriate spot on the scale.

Emotions listed included: Angry, Hateful, Scared, Fearful, Sad, Guilty, Proud, and Ashamed. 
Figure 1: Percent of Respondents Exposed to Hate Material in Six Nations

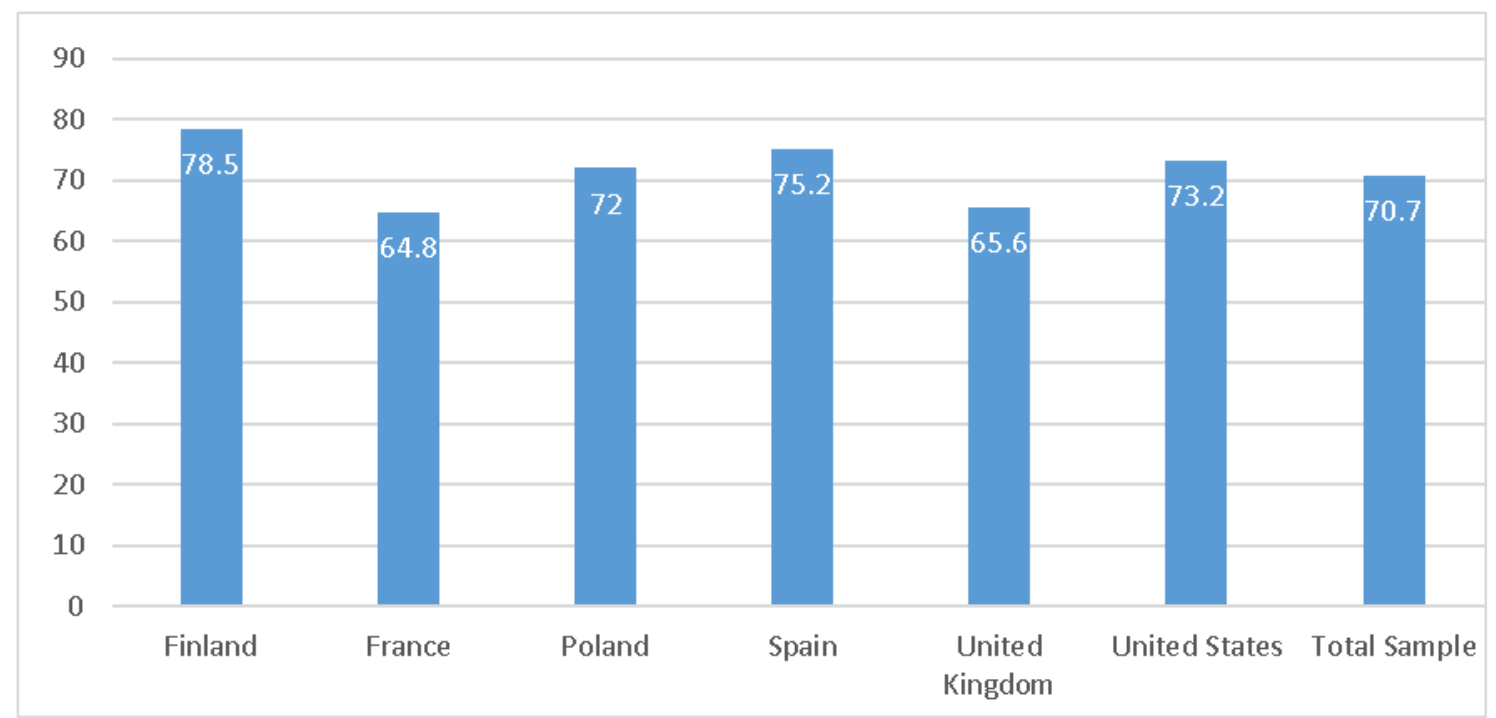

Figure 1 shows the percentage of respondents by nation that stated they were exposed to hateful or degrading writings or speech online that attacked certain groups of people or individuals within the three months preceding the data collection. 
Figure 2: Frequency of Respondent Exposure to Hate Materials in Six Nations

\begin{tabular}{|c|c|c|c|c|c|c|c|}
\hline \multicolumn{8}{|l|}{$100.00 \%$} \\
\hline & $20.3 \%$ & $14.9 \%$ & $9.6 \%$ & $14.8 \%$ & $14.2 \%$ & & $16.4 \%$ \\
\hline \multicolumn{8}{|l|}{$80.00 \%$} \\
\hline $70.00 \%$ & $=$ & & & & & & \\
\hline \multicolumn{8}{|l|}{$60.00 \%$} \\
\hline $50.00 \%$ & $53.3 \%$ & & & & & $41.2 \%$ & \\
\hline $40.00 \%$ & & & & & & & \\
\hline \multicolumn{8}{|l|}{$30.00 \%$} \\
\hline \multicolumn{8}{|l|}{$20.00 \%$} \\
\hline \multicolumn{8}{|l|}{$10.00 \%$} \\
\hline \multirow[t]{3}{*}{$0.00 \%$} & $4.9 \%$ & $11.2 \%$ & $6.0 \%$ & & & $9.8 \%$ & $11.3 \%$ \\
\hline & Finland & France & Poland & Spain & $\begin{array}{c}\text { United } \\
\text { Kingdom }\end{array}$ & United States & Total Sample \\
\hline & & - Never & — Infrequently & - Occasionally & Frequ & ntly & \\
\hline
\end{tabular}

Figure 2 shows the frequency that respondents were exposed to hateful or degrading materials that attacked groups or individuals, by nation. 
Figure 3: Internet Platforms Where Respondents Viewed Hate Materials in Six Nations

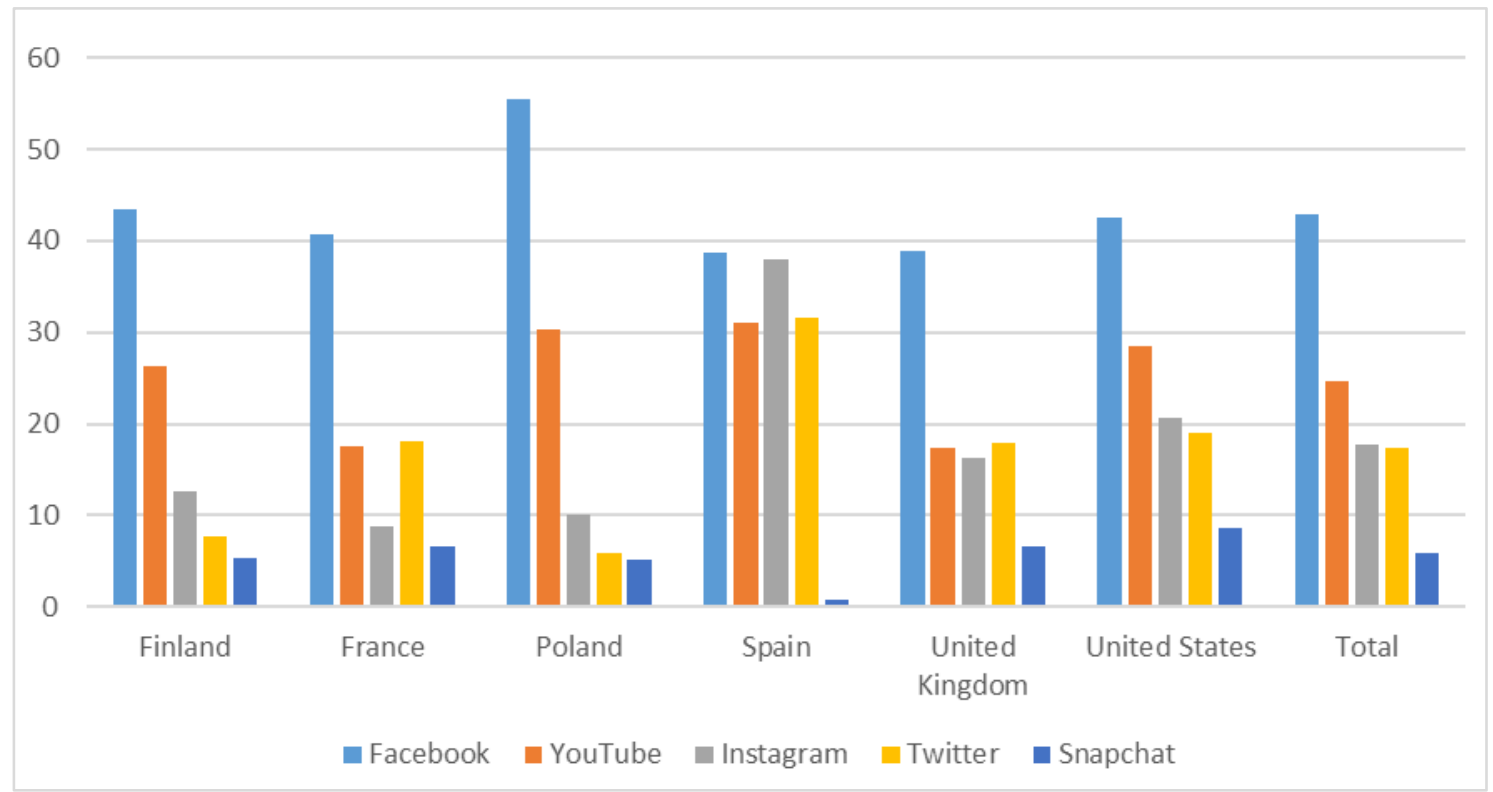

Figure 3 shows the online platforms where respondents were exposed to hateful or degrading materials that attacked groups or individuals, by nation. 
Figure 4: How Respondents Arrived at Hate-Containing Site in Six Nations

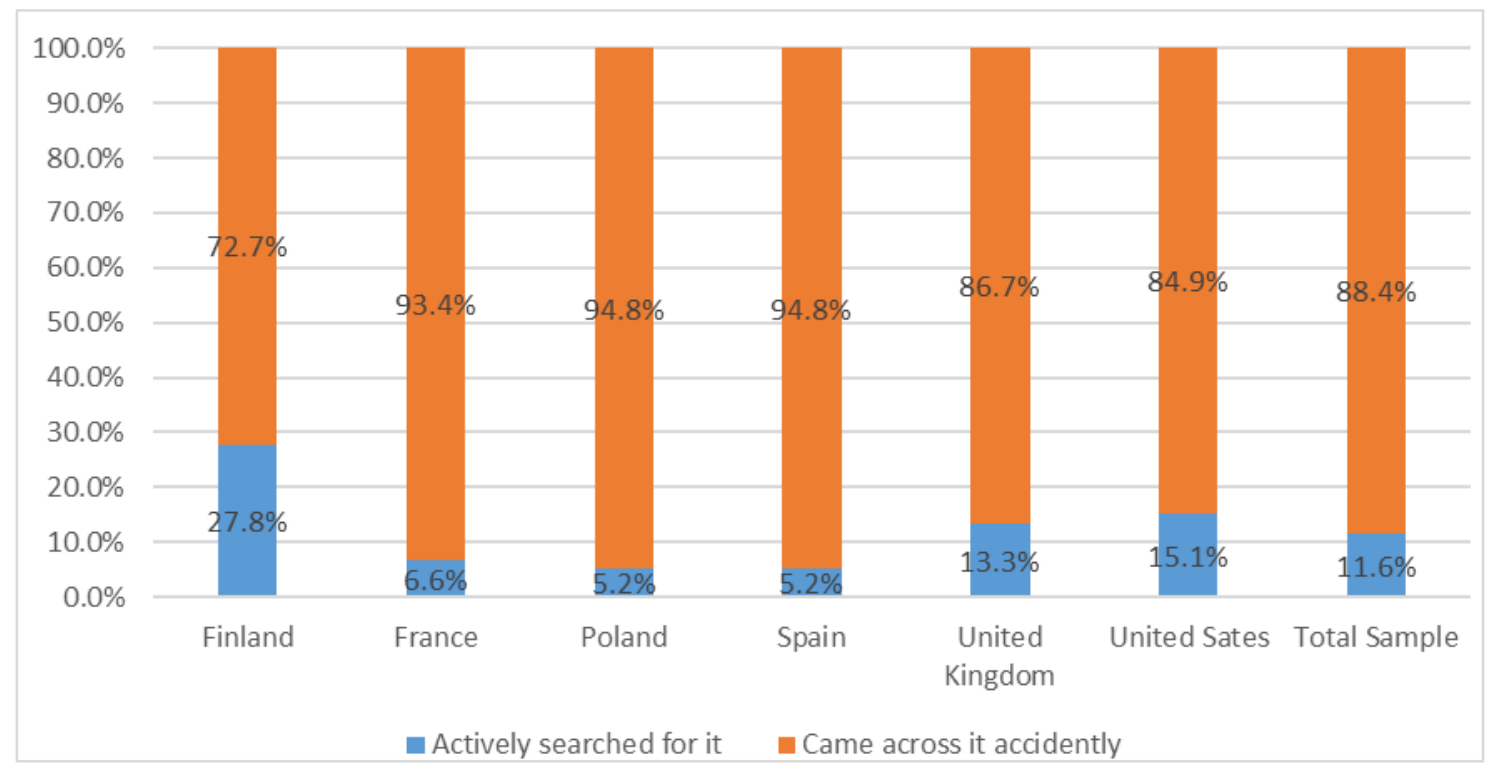

Figure 4 shows the percentage of respondents who actively sought out hateful or degrading materials that attacked groups or individuals versus those who accidentally came across it, by nation. 
Table 1: Type of Hate Expressed in Six Nations

\begin{tabular}{|c|c|c|c|c|c|c|c|}
\hline & $\begin{array}{c}\text { Total } \\
\text { Sample }\end{array}$ & Finland & France & Poland & Spain & U.K. & U.S.A. \\
\hline $\begin{array}{l}\text { Advocate } \\
\text { Violence } \\
\text { against Group }\end{array}$ & $\begin{array}{c}610 \\
23.5 \%\end{array}$ & $\begin{array}{c}37 \\
15.0 \%\end{array}$ & $\begin{array}{c}100 \\
20.5 \%\end{array}$ & $\begin{array}{c}68 \\
17.5 \%\end{array}$ & $\begin{array}{c}137 \\
35.4 \%\end{array}$ & $\begin{array}{c}117 \\
22.7 \%\end{array}$ & $\begin{array}{c}151 \\
26.6 \%\end{array}$ \\
\hline $\begin{array}{l}\text { Use } \\
\text { Stereotypes to } \\
\text { Describe } \\
\text { Group }\end{array}$ & $\begin{array}{c}1132 \\
43.7 \%\end{array}$ & $\begin{array}{c}139 \\
56.3 \%\end{array}$ & $\begin{array}{c}196 \\
40.3 \%\end{array}$ & $\begin{array}{c}165 \\
42.4 \%\end{array}$ & $\begin{array}{c}162 \\
41.8 \%\end{array}$ & $\begin{array}{c}197 \\
38.3 \%\end{array}$ & $\begin{array}{c}273 \\
48.1 \%\end{array}$ \\
\hline $\begin{array}{l}\text { Blame Group } \\
\text { for Personal } \\
\text { Problems } \\
\end{array}$ & $\begin{array}{c}678 \\
26.2 \%\end{array}$ & $\begin{array}{c}69 \\
27.9 \%\end{array}$ & $\begin{array}{c}106 \\
21.8 \%\end{array}$ & $\begin{array}{c}75 \\
19.3 \%\end{array}$ & $\begin{array}{c}86 \\
22.2 \%\end{array}$ & $\begin{array}{c}138 \\
26.8 \%\end{array}$ & $\begin{array}{c}204 \\
36.0 \%\end{array}$ \\
\hline $\begin{array}{l}\text { Blame Group } \\
\text { for National } \\
\text { Problems }\end{array}$ & $\begin{array}{c}683 \\
26.4 \%\end{array}$ & $\begin{array}{c}63 \\
25.6 \%\end{array}$ & $\begin{array}{c}117 \\
24.0 \%\end{array}$ & $\begin{array}{c}82 \\
21.1 \%\end{array}$ & $\begin{array}{c}101 \\
26.1 \%\end{array}$ & $\begin{array}{c}139 \\
27.0 \%\end{array}$ & $\begin{array}{c}181 \\
31.9 \%\end{array}$ \\
\hline $\begin{array}{l}\text { Advocate } \\
\text { Hatred of } \\
\text { Group }\end{array}$ & $\begin{array}{c}816 \\
31.5 \%\end{array}$ & $\begin{array}{c}107 \\
43.3 \%\end{array}$ & $\begin{array}{c}135 \\
27.7 \%\end{array}$ & $\begin{array}{c}120 \\
30.8 \%\end{array}$ & $\begin{array}{c}158 \\
40.8 \%\end{array}$ & $\begin{array}{c}121 \\
23.5 \%\end{array}$ & $\begin{array}{c}175 \\
30.9 \%\end{array}$ \\
\hline $\begin{array}{l}\text { Call for } \\
\text { Discrimination } \\
\text { against Group }\end{array}$ & $\begin{array}{c}497 \\
19.2 \%\end{array}$ & $\begin{array}{c}45 \\
18.3 \%\end{array}$ & $\begin{array}{c}82 \\
16.8 \%\end{array}$ & $\begin{array}{c}69 \\
17.7 \%\end{array}$ & $\begin{array}{c}111 \\
28.7 \%\end{array}$ & $\begin{array}{c}79 \\
15.3 \%\end{array}$ & $\begin{array}{c}111 \\
19.6 \%\end{array}$ \\
\hline Sample Size & 2,592 & 247 & 487 & 389 & 387 & 515 & 567 \\
\hline
\end{tabular}

Table 1 shows the breakdown of the type of hate that was encouraged in the hateful or degrading materials respondents viewed, by nation. 
Table 2: Focus of Hate and the Targeted Groups in Six Nations

\begin{tabular}{|l|c|c|c|c|c|c|c|}
\hline & $\begin{array}{c}\text { Total } \\
\text { Sample }\end{array}$ & Finland & France & Poland & Spain & U.K. & U.S.A. \\
\hline Ethnicity or Race & 964 & 90 & 143 & 147 & 102 & 201 & 281 \\
& $37.2 \%$ & $36.4 \%$ & $29.4 \%$ & $37.8 \%$ & $26.4 \%$ & $39.0 \%$ & $49.6 \%$ \\
\hline Nationality or & 853 & 125 & 138 & 149 & 122 & 155 & 164 \\
Immigrant Status & $32.9 \%$ & $50.6 \%$ & $28.3 \%$ & $38.3 \%$ & $31.5 \%$ & $30.1 \%$ & $28.9 \%$ \\
\hline Sexual Orientation & 889 & 93 & 146 & 153 & 163 & 133 & 201 \\
& $34.3 \%$ & $37.7 \%$ & $30.0 \%$ & $39.3 \%$ & $42.1 \%$ & $25.8 \%$ & $35.4 \%$ \\
\hline Religious & 640 & 81 & 123 & 118 & 52 & 124 & 142 \\
Conviction and & $24.7 \%$ & $32.8 \%$ & $25.3 \%$ & $30.3 \%$ & $13.4 \%$ & $24.1 \%$ & $25.0 \%$ \\
Belief & 615 & 59 & 84 & 107 & 117 & 87 & 161 \\
\hline Political Views & $23.7 \%$ & $23.9 \%$ & $17.3 \%$ & $27.5 \%$ & $30.2 \%$ & $16.9 \%$ & 28.4 \\
\hline Sex/Gender/Gender & 686 & 57 & 99 & 75 & 165 & 112 & 178 \\
Identity & $26.5 \%$ & $23.1 \%$ & $20.4 \%$ & $19.3 \%$ & $42.6 \%$ & $21.7 \%$ & $31.4 \%$ \\
\hline Disability Status & 223 & 16 & 32 & 34 & 46 & 33 & 62 \\
& $8.6 \%$ & $6.5 \%$ & $6.6 \%$ & $8.7 \%$ & $11.9 \%$ & $6.4 \%$ & $10.9 \%$ \\
\hline Appearance & 470 & 49 & 91 & 83 & 85 & 64 & 98 \\
& $18.1 \%$ & $19.8 \%$ & $18.7 \%$ & $21.3 \%$ & $22.0 \%$ & $12.4 \%$ & $17.3 \%$ \\
\hline Sample Size & 2,592 & 247 & 487 & 389 & 387 & 515 & 567 \\
\hline
\end{tabular}

Table 2 shows the breakdown of the groups that were targeted in the hateful or degrading materials that the respondents viewed, by nation. 
Table 3: Respondent Emotions Evoked by Hate Messages in Six Nations

\begin{tabular}{|l|c|c|c|c|c|c|c|c|}
\hline & Angry & Hateful & Scared & Fearful & Sad & Guilty & Proud & Ashamed \\
\hline \multirow{2}{*}{ Finland } & 55.3 & 41.8 & 28.0 & 23.8 & 56.7 & 14.8 & 14.2 & 45.1 \\
& 171 & 153 & 136 & 125 & 161 & 113 & 100 & 154 \\
\hline \multirow{2}{*}{ France } & 67.6 & 47.6 & 35.9 & 38.5 & 66.9 & 26.3 & 18.1 & 50.3 \\
& 274 & 242 & 234 & 229 & 269 & 210 & 172 & 246 \\
\hline \multirow{2}{*}{ Poland } & 54.8 & 28.8 & 28.6 & 24.8 & 55.1 & 15.3 & 15.5 & 40.1 \\
& 238 & 210 & 204 & 196 & 230 & 182 & 160 & 204 \\
\hline \multirow{2}{*}{ Spain } & 73.4 & 47.8 & 37.1 & 34.3 & 71.8 & 17.9 & 11.3 & 61.7 \\
& 271 & 246 & 224 & 209 & 259 & 175 & 151 & 245 \\
\hline United & 67.6 & 39.8 & 37.6 & 38.2 & 66.1 & 28.1 & 16.7 & 52.7 \\
Kingdom & 304 & 276 & 267 & 267 & 298 & 253 & 234 & 292 \\
\hline United & 65.8 & 42.2 & 37.3 & 38.5 & 66.8 & 25.4 & 21.6 & 51.6 \\
States & 383 & 348 & 341 & 343 & 379 & 316 & 285 & 350 \\
\hline Total & 65.0 & 41.6 & 34.9 & 34.5 & 64.8 & 22.6 & 17.0 & 51.0 \\
Sample & 1640 & 1474 & 1406 & 1368 & 1596 & 1249 & 1101 & 1491 \\
\hline
\end{tabular}

Table 3 shows the breakdown of emotions that the respondents reported feeling after viewing the hateful or degrading materials, by nation. 